\title{
Mineralização óssea na tíbia em frangos de corte alimentados com dietas contendo diferentes níveis e fontes de zinco e manganês
}

\author{
Bone mineralization in broilers fed diets containing different levels and sources of zinc \\ and manganese
}

\author{
Bruna Helena Carvalho Pacheco*, Daniel Emygdio de Faria Filho, Karina Márcia Ribeiro de Souza \\ Nascimento, Amanda Raquel de Miranda Caniatto, Mariene Miyoko Natori e Douglas Emygdio de Faria \\ Universidade de São Paulo, Pirassununga, SP, Brasil. *Autor para correspondência: brunahcp@yahoo.com.br.
}

Submissão:23/11/2017 / Aceite: 01/07/2019

\begin{abstract}
RESUMO
Objetivou-se estimar nível ótimo de zinco e de manganês de frangos aos 21 e 42 dias, e comparar métodos para quantificar a mineralização óssea, confiabilidade do teste, tempo de execução e efeito da extração da gordura, visando viabilizar procedimento técnico mais prático em termos laboratoriais. Em cada experimento, foram distribuídos 320 pintinhos machos em gaiolas metabólicas, em delineamento inteiramente casualizado, com oito tratamentos e cinco repetições de oito aves cada. No experimento 1, a inclusão de sulfato de zinco foi de 0,60 e $100 \mathrm{mg} / \mathrm{kg}$ e de zinco metionina de 20, 40, 60, 80 e $100 \mathrm{mg} / \mathrm{kg}$. No experimento 2, o sulfato de manganês adicionado foi de 0,65 e $100 \mathrm{mg} / \mathrm{kg}$ e de manganês metionina de 25, 45, 65, 85 e $105 \mathrm{mg} / \mathrm{kg}$. O zinco e manganês não interferiram nas características ósseas, independente da fonte e nível. A mineralização óssea aumentou conforme elevou-se a concentração dos microminerais, independente da fonte em que estes foram estudados. O método mais adequado para determinação do teor de zinco e de manganês é com a utilização de tíbias. Não há necessidade de extração de gordura da tíbia para determinação do teor de zinco ou de manganês e a análise pode ser realizada com menor tempo de execução sem detrimento dos resultados.
\end{abstract}

PALAVRAS-CHAVE: aves, exigência, mineral, ossos.

\begin{abstract}
The objective of this study was to estimate the optimal zinc and manganese levels for bone mineralization of broilers at 21 and 42 days of age, besides the methods comparison for quantifying the degree of bone mineralization, reliability test, execution time and effect of fat extraction, aiming to make feasible a more practical technical procedure in laboratory terms. In each experiment, 320 male chicks were housed in iron mesh metabolic cages, distributed according to a completely randomized experimental design in eight treatments with five replicates of eight birds each. In experiment 1 , zinc sulfate was included at 0,60 , and $100 \mathrm{mg} / \mathrm{kg}$ and zinc methionine at 20,40,60,80, and $100 \mathrm{mg} / \mathrm{kg}$. In experiment 2, manganese sulfate was added at 0,65 , and $105 \mathrm{mg} / \mathrm{kg}$ and manganese methionine at 25, 45, 65, 85, and $105 \mathrm{mg} / \mathrm{kg}$. The evaluated trace minerals (zinc and manganese) did not interfere in the evaluated bone characteristics, regardless of source or level. The degree of bone mineralization increased according to the concentration of zinc and manganese in the diet, regardless of source of these trace elements. The most appropriate method to determine the zinc and manganese content is with the use of tibias. There is no need to extract fat from the tibia to determine the zinc or manganese content, and the analysis can be performed with less time of execution without detriment of the results.
\end{abstract}

KEYWORDS: avian, requirements, mineral, bones.

\section{INTRODUÇÃO}

Com o progresso genético dos frangos de corte, é de extrema importância a constante atualização das exigências minerais em relação ao desempenho, mineralização óssea e resposta imune (SUTTLE 2010). Na nutrição moderna das aves os microminerais são essenciais, pois atuam em muitos processos metabólicos nos organismos vivos (AKSU et al. 2012). Através da realização de estudos experimentais são determinadas as exigências, as quais variam de acordo com o sexo e a fase de criação, normalmente 
reduzindo com o avanço da idade da ave (GOMES et al. 2009).

A absorção de minerais inorgânicos pelos frangos de corte é limitada, principalmente devido a sua tendência de formar complexos com outros componentes da dieta que estão menos disponíveis ou indisponíveis, e a sua tendência de interferir com o outro mineral no aparelho digestivo (YAN \& WALDROUP 2006). De acordo com o mesmo, a biodisponibilidade absoluta de minerais inorgânicos é geralmente baixa e isto significa que uma parte destes nutrientes minerais passa através do trato gastrintestinal e acabam na excreta.

Já os microminerais orgânicos por apresentarem alta disponibilidade são melhores aproveitados devido a maior absorção do mineral nessa forma, sendo assim, é vantajoso seu uso na nutrição dos frangos de corte (SUNDER et al. 2013).

ŚWIĄTKIEWICZ et al. (2014) ao analisarem seus dados experimentais, observaram que a biodisponibilidade e a eficácia das fontes orgânicas de $\mathrm{Zn}, \mathrm{Mn}$ e $\mathrm{Cu}$ são superiores às inorgânicas. Segundo o autor, tal uso pode reduzir a excreção de minerais, desta forma, reduzir os potenciais efeitos nocivos da produção intensiva de aves sobre o meio ambiente.

De acordo com GARCIA \& DALE (2006) a necessidade de quantificar a mineralização óssea tem sido reconhecida por pesquisadores da área de nutrição e fisiologia das aves. $O$ ensaio mais comumente utilizado para este propósito atualmente é através das cinzas do osso da tíbia, conforme a técnica descrita pela AOAC (2000).

Objetivou-se estimar o nível ótimo de zinco e de manganês para a mineralização óssea de frangos de corte aos 21 e 42 dias de idade, além de comparar métodos para quantificar o grau de mineralização óssea (da tíbia, do tarso-metatarso e das falanges), avaliar a confiabilidade do teste, tempo de execução e o efeito da extração da gordura na determinação dessas características.

\section{MATERIAL E MÉTODOS}

Foram conduzidos dois experimentos no Laboratório de Avicultura do Departamento de Zootecnia da Faculdade de Zootecnia e Engenharia de Alimentos (FZEA), Universidade de São Paulo (USP), Campus de Pirassununga. As aves foram alojadas em 40 gaiolas metabólicas de arame galvanizado $(0,9 \mathrm{~m} \times 0,7 \mathrm{~m} \times$ $0,5 \mathrm{~m}$ ) com bebedouro tipo nipple reguláveis, comedouro tipo calha e bandeja para colheita de excretas.

Em cada um dos experimentos foram distribuídos 320 pintinhos machos da linhagem Cobb-500 do $1^{\circ}$ ao $42^{\circ}$ dia de idade. A unidade experimental foi constituída por oito aves até 21 dias de idade e por seis aves até 42 dias de idade.

Em ambos os experimentos, as aves foram distribuídas em delineamento experimental inteiramente casualizado, com oito tratamentos e cinco repetições. No experimento 1, os tratamentos consistiram em concentrações formuladas, adicionando-se níveis crescentes de sulfato de zinco (ZnSO4 (35\% Zn) - Zn inorgânico) e de zinco metionina (Zinpro® (10\% Zn) - Zn orgânico), como indicado na Tabela 1.

Tabela 1. Indicação das dietas experimentais do experimento 1 (Zinco).

Table 1. Description of the experimental diets of experiment 1 (Zinc).

\begin{tabular}{|c|c|c|}
\hline Tratamentos & Micromineral & Nível de inclusão $(\mathrm{mg} / \mathrm{kg})$ \\
\hline 1 & Sem Zn & 0 \\
\hline 2 & Zn inorgânico & 60 \\
\hline 3 & Zn inorgânico & 100 \\
\hline 4 & Zn orgânico & 20 \\
\hline 5 & Zn orgânico & 40 \\
\hline 6 & Zn orgânico & 60 \\
\hline 7 & Zn orgânico & 80 \\
\hline 8 & Zn orgânico & 100 \\
\hline
\end{tabular}

No experimento 2, os tratamentos consistiram em concentrações formuladas, adicionando-se níveis crescentes de sulfato de manganês (MnSO4 (31\% Mn) - Mn inorgânico) e de manganês metionina ( $\mathrm{Mn}$ Zinpro® (8\% Mn) - Mn orgânico), como indicado na Tabela 2.

No experimento 1 (Tabela 3) e no experimento 2 (Tabela 4) as dietas referências foram à base de milho e farelo de soja. As dietas testes receberam a inclusão dos microminerais e foram baseadas em ROSTAGNO et al. (2005) para frangos de corte com desempenho médio. Os fatores em questão foram níveis de zinco e de manganês, na fonte orgânica e inorgânica, em dietas isocalóricas e isoprotéicas para cada uma das fases. 
Tabela 2. Indicação das dietas experimentais do experimento 2 (Manganês).

Table 2. Description of the experimental diets of experiment 2 (Manganese).

\begin{tabular}{|c|c|c|}
\hline Tratamentos & Micromineral & Nível de inclusão $(\mathrm{mg} / \mathrm{kg})$ \\
\hline 1 & Sem Mn & 0 \\
\hline 2 & Mn inorgânico & 65 \\
\hline 3 & Mn inorgânico & 105 \\
\hline 4 & Mn orgânico & 25 \\
\hline 5 & Mn orgânico & 45 \\
\hline 6 & Mn orgânico & 65 \\
\hline 7 & Mn orgânico & 85 \\
\hline 8 & Mn orgânico & 105 \\
\hline
\end{tabular}

Tabela 3. Composição de ingredientes das dietas experimentais nas fases de 1 a 21 e de 22 a 42 dias de idade de frangos de corte, sem a suplementação do zinco (Experimento 1).

Table 3. Ingredient composition of the experimental diets for the phases from 1 to 21 and from 22 to 42 days of age, without zinc supplementation (Experiment 1).

\begin{tabular}{|c|c|c|}
\hline \multirow[t]{2}{*}{ Ingredientes } & \multicolumn{2}{|c|}{ Fases Experimentais (dias) } \\
\hline & 1 a 21 & 22 a 42 \\
\hline Milho Grão & 53,1 & 62,0 \\
\hline Farelo de Soja & 37,6 & 30,8 \\
\hline Óleo de Soja & 3,10 & 3,31 \\
\hline Fosfato Bicalcico & 1,94 & 1,65 \\
\hline Calcário Calcítico & 0,93 & 0,85 \\
\hline Sal comum & 0,41 & 0,37 \\
\hline DL-metionina & 0,36 & 0,23 \\
\hline L-Lisina HCL & 0,33 & 0,20 \\
\hline Bicarbonato de Sódio & 0,15 & 0,15 \\
\hline L-Treonina & 0,14 & 0,05 \\
\hline Cloreto de Colina & 0,05 & 0,05 \\
\hline Suplemento mineral vitamínico (sem Zn $)^{1}$ & 0,40 & 0,40 \\
\hline Butil-Hidróxi-Tolueno (BHT ) & 0,01 & 0,01 \\
\hline Inerte & 1,46 & - \\
\hline TOTAL & 100,0 & 100,0 \\
\hline \multicolumn{3}{|l|}{ Composição Calculada (\%) } \\
\hline Energia Metabolizável (kcal/kg) & 2950 & 3100 \\
\hline Proteína Bruta & 22,0 & 19,4 \\
\hline Extrato Etéreo & 5,59 & 6,02 \\
\hline Cálcio & 0,94 & 0,82 \\
\hline Fósforo disponível & 0,47 & 0,41 \\
\hline Sódio & 0,22 & 0,20 \\
\hline Cloro & 0,29 & 0,26 \\
\hline Potássio & 0,84 & 0,74 \\
\hline Lisina digestível & 1,33 & 1,07 \\
\hline Metionina + cistina digestível & 0,94 & 0,77 \\
\hline Metionina digestível & 0,66 & 0,51 \\
\hline Treonina digestível & 0,86 & 0,70 \\
\hline Triptofano digestível & 0,24 & 0,21 \\
\hline Zinco $(\mathrm{mg} / \mathrm{kg})$ & 33,0 & 31,7 \\
\hline
\end{tabular}

${ }^{1}$ Suplemento mineral vitamínico (sem Zn). Níveis de garantia por kg do produto: Ferro $=12,50 \mathrm{~g}$, Manganês $=17,50 \mathrm{~g}$, Cobre $=2.000,00 \mathrm{mg}$, lodo $=300,00 \mathrm{mg}$, Selênio $=50,00 \mathrm{mg}$, VIT A $=1.750 .000,00 \mathrm{UI}$, VIT D3 $=550.000,00 \mathrm{UI}$, VIT E $=$ $2.750,00, \mathrm{VIT} \mathrm{K3}=400,00 \mathrm{mg}, \mathrm{VIT} B 1=500,00 \mathrm{mg}, \mathrm{VIT} B 2=1.250,00 \mathrm{mg}, \mathrm{VIT} \mathrm{B} 6=750,00 \mathrm{mg}, \mathrm{VIT}$ B12 $=3.000,00 \mathrm{mcg}$, Colina $=78,12 \mathrm{~g}$, Niacina $=8.750,00 \mathrm{mg}$, Ac. Pantotênico $=3.250,00 \mathrm{mg}$. Ac. Fólico $=200,00 \mathrm{mg}, \mathrm{BHT}=25,00 \mathrm{~g}$, Virginiamicina $=2.500,00 \mathrm{mg}$, Monensina $=25,00 \mathrm{~g}$.

No Laboratório de Minerais da Faculdade de Zootecnia e Engenharia de Alimentos (FZEA/USP) foram determinados os níveis de zinco (Tabela 5) e de manganês (Tabela 6) contido nas dietas, através da análise de espectrofotometria de absorção atômica, equipamento da marca Perkin Elmer - AAS 100, seguindo a metodologia da AOAC (1995). 
Tabela 4. Composição de ingredientes das dietas experimentais nas fases de 1 a 21 e de 22 a 42 dias de idade de frangos de corte, sem a suplementação do manganês (Experimento 2).

Table 4. Ingredient composition of the experimental diets for the phases from 1 to 21 and from 22 to 42 days of age, without manganese supplementation (Experiment 2).

\begin{tabular}{|c|c|c|}
\hline \multirow[t]{2}{*}{ Ingredientes } & \multicolumn{2}{|c|}{ Fases Experimentais (dias) } \\
\hline & 1 a 21 & 22 a 42 \\
\hline Milho Grão & 53,1 & 62,0 \\
\hline Farelo de Soja & 37,6 & 30,8 \\
\hline Óleo de Soja & 3,10 & 3,31 \\
\hline Fosfato Bicálcico & 1,94 & 1,65 \\
\hline Calcário Calcítico & 0,93 & 0,85 \\
\hline Sal comum & 0,41 & 0,37 \\
\hline DL-metionina & 0,36 & 0,23 \\
\hline L-Lisina HCL & 0,33 & 0,20 \\
\hline Bicarbonato de Sódio & 0,15 & 0,15 \\
\hline L-Treonina & 0,14 & 0,05 \\
\hline Cloreto de Colina & 0,05 & 0,05 \\
\hline Suplemento mineral vitamínico (sem Mn)1 & 0,40 & 0,40 \\
\hline Butil-Hidróxi-Tolueno (BHT ) & 0,01 & 0,01 \\
\hline Inerte & 1,46 & - \\
\hline$\overline{\text { TOTAL }}$ & 100,0 & 100,0 \\
\hline \multicolumn{3}{|l|}{ Composição Calculada (\%) } \\
\hline Energia Metabolizável (kcal/kg) & 2950 & 3100 \\
\hline Proteína Bruta & 22,0 & 19,4 \\
\hline Extrato Etéreo & 5,59 & 6,02 \\
\hline Cálcio & 0,94 & 0,82 \\
\hline Fósforo disponível & 0,47 & 0,41 \\
\hline Sódio & 0,22 & 0,20 \\
\hline Cloro & 0,29 & 0,26 \\
\hline Potássio & 0,84 & 0,74 \\
\hline Lisina digestível & 1,33 & 1,07 \\
\hline Metionina + cistina digestível & 0,94 & 0,77 \\
\hline Metionina digestível & 0,66 & 0,51 \\
\hline Treonina digestível & 0,86 & 0,70 \\
\hline Triptofano digestível & 0,24 & 0,21 \\
\hline Manganês (mg/kg) & 37,8 & 34,9 \\
\hline \multicolumn{3}{|c|}{ 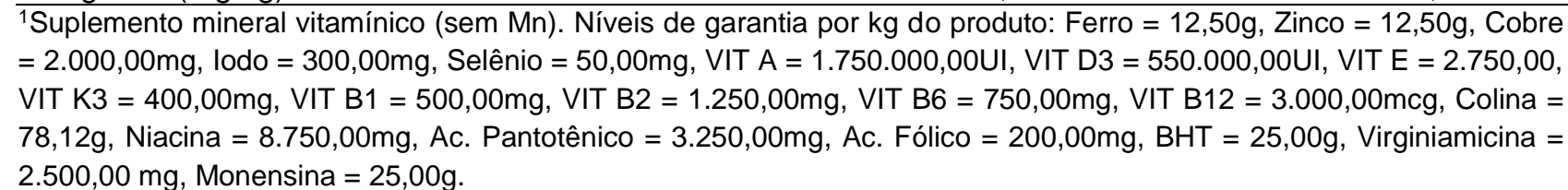 } \\
\hline
\end{tabular}

Tabela 5. Teor de zinco analisado ( $\mathrm{mg} / \mathrm{kg}$ ) contido nas dietas experimentais (Experimento 1). Table 5. Analyzed Zinc content ( $\mathrm{mg} / \mathrm{kg}$ ) in the experimental diets (Experiment 1).

\begin{tabular}{ccc}
\hline Tratamentos & 21 dias de idade & 42 dias de idade \\
2 & 33,0 & 31,7 \\
3 & 78,0 & 95,5 \\
4 & 153,0 & 126,0 \\
5 & 48,5 & 68,7 \\
6 & 89,7 & 85,0 \\
7 & 106,0 & 101,2 \\
8 & 136,7 & 137,0 \\
\hline
\end{tabular}

As aves receberam alimento e água ad libitum e o mesmo manejo durante todo o período experimental. O programa de luz adotado durante o experimento foi contínuo (24 horas de luz). 0 monitoramento da temperatura e da umidade relativa do ar foi realizado por termohigrômetro, alocados a altura intermediária das gaiolas. No experimento 1, as temperaturas médias (máxima e mínima) foram registradas em $31,61 \pm 1,95 \stackrel{\circ}{\circ} \mathrm{C}$ e $24,43 \pm 2,25 \stackrel{\circ}{\circ} \mathrm{C}$, respectivamente. Os valores médios obtidos para 
umidade relativa do ar foram de $29,26 \pm 7,27 \%$ a máxima e de $22,20 \pm 3,47 \%$ a mínima. No experimento 2 , as temperaturas médias (máxima e mínima) foram registradas em $31,22 \pm 1,94{ }^{\circ} \mathrm{C}$ e $24,75 \pm 2,06{ }^{\circ} \mathrm{C}$, respectivamente. Os valores médios obtidos para umidade relativa do ar foram de $45,20 \pm 12,31 \%$ a máxima e de $32,75 \pm 9,98 \%$ a mínima.

Tabela 6. Teor de manganês analisado ( $\mathrm{mg} / \mathrm{kg}$ ) contido nas dietas experimentais (Experimento 2). Table 6. Analyzed Manganese content ( $\mathrm{mg} / \mathrm{kg}$ ) in the experimental diets (Experiment 2).

\begin{tabular}{ccc}
\hline Tratamentos & 21 dias de idade & 42 dias de idade \\
\cline { 1 - 2 } 3 & 37,8 & 34,9 \\
3 & 126,8 & 63,0 \\
4 & 133,6 & 103,1 \\
6 & 60,5 & 55,4 \\
7 & 76,2 & 63,3 \\
8 & 86,3 & 70,4 \\
& 123,7 & 83,9 \\
\end{tabular}

No incubatório, as aves receberam a vacina contra Marek ao nascimento e no sétimo dia de idade as aves foram submetidas à vacinação ocular contra as doenças de NewCastle e Gumboro (Biovet@).

Nos dois experimentos, para avaliação das características ósseas, aos 21 e 42 dias de idade, duas aves por repetição foram abatidas por deslocamento cervical, removendo as tíbias, tarso-metatarso e as falanges. Estas estruturas foram identificadas, embaladas e congeladas para posterior determinação das cinzas.

As falanges foram removidas da perna direita e o tarso-metatarso da perna esquerda, depois secas a $105{ }^{\circ} \mathrm{C}$ na estufa por 72 horas. Conforme o método descrito por GARCIA \& DALE (2004) as amostras seriam queimadas sem a extração lipídica, no entanto, houve uma modificação da técnica, no qual foi realizada a extração lipídica (por oito horas à $80 \stackrel{\circ}{\circ}$ ) das amostras antes de serem queimadas na mufla a $550 \pm 50 \stackrel{\circ}{ } \mathrm{C}$ por quatro horas.

A tíbia retirada da perna direita foi submetida à extração lipídica antes de ser incinerada, de acordo com o procedimento padrão de avaliação descrito pela AOAC (2000). A tíbia retirada da perna esquerda foi incinerada sem a extração lipídica conforme procedimentos realizados por YAN et al. (2005) em que foi feita a comparação da extração lipídica, com os ossos da mesma ave. No Laboratório de Minerais da Faculdade de Zootecnia e Engenharia de Alimentos (FZEA/USP) foram determinados os níveis de zinco contido nas tíbias, tarso-metatarso e falanges.

Além da determinação do mineral na matéria original, foi realizada a contagem do tempo de execução de cada um dos métodos estudados e também na tíbia foi avaliado o peso, comprimento e largura.

A determinação da disponibilidade do mineral foi de acordo com o método Slope Ratio descrito por SAKOMURA \& ROSTAGNO (2007). No experimento 1, foi comparado um tratamento sem zinco, com outros dois tratamentos com níveis de zinco inorgânico (60 e $100 \mathrm{mg} / \mathrm{kg}$ ) e mais outros dois tratamentos com níveis de zinco orgânico (60 e $100 \mathrm{mg} / \mathrm{kg}$ ). No experimento 2, foi comparado um tratamento sem manganês, com outros dois tratamentos com níveis de manganês inorgânico (65 e $105 \mathrm{mg} / \mathrm{kg}$ ) e mais outros dois tratamentos com níveis de manganês orgânico (65 e $105 \mathrm{mg} / \mathrm{kg}$ ).

A biodisponibilidade relativa do zinco e do manganês orgânico foi calculada através das equações de regressões das fontes dos microminerais estudados, para qual se estabeleceu o valor $100 \%$ ao zinco e ao manganês na fonte inorgânica.

Os dados foram submetidos à análise de variância com auxílio do programa estatístico SAS (2004) e as médias foram comparadas pelo teste de Tukey a $5 \%$ de probabilidade.

\section{RESULTADOS E DISCUSSÃO}

No experimento 1 , não houve efeito $(p>0,05)$ dos tratamentos para a tíbia direita e esquerda (peso, comprimento e altura) e no peso do tarso-metatarso e das falanges (Tabelas 7 e 8). Concordando com SUNDER et al. (2013) os quais não encontraram diferenças no peso e comprimento das tíbias, indicando a não influência do mineral orgânico e reafirmando que a suplementação mínima de zinco foi suficiente para manter uma boa estrutura óssea (SUNDER et al. 2011). Discordando de BAO \& CHOCT (2009) que observaram um maior comprimento da tíbia conforme foi aumentada a inclusão de zinco orgânico na dieta.

Avaliando-se o teor de zinco na tíbia direita e esquerda, no tarso-metatarso e nas falanges, observouse que houve resposta estatística aos 21 dias de idade das aves para a tíbia direita $(p<0,0004)$ 
$(Y=-0,0137 X 2+2,0602 X+150,2$ (TDZn I - Tíbia direita zinco inorgânico) e $Y=0,8404 X+151,87$ (TDZnO - Tíbia direita zinco orgânico)) e tíbia esquerda $(p<0,02)(Y=-0,0171 X 2+2,2348 X+128,46$ (TEZn I Tíbia esquerda zinco inorgânico) e $Y=0,6772 X+131,28$ (TEZnO - Tíbia esquerda zinco orgânico)) (Tabela 9).

Tabela 7. Valores médios para as características ósseas de frangos de corte aos 21 e aos 42 dias de idade, conforme níveis de zinco na fonte orgânica e inorgânica na dieta (Experimento 1).

Table 7. Mean values for bone characteristics of broiler chickens at 21 and 42 days of age, according to zinc levels in organic and inorganic sources in the diet (Experiment 1).

\begin{tabular}{|c|c|c|c|c|c|c|c|}
\hline \multirow{3}{*}{ Variável } & \multicolumn{5}{|c|}{ Zinco $(\mathrm{mg} / \mathrm{kg})$} & \multirow{3}{*}{$\mathrm{CV}(\%)$} & \multirow{3}{*}{ Valor $\mathrm{P}$} \\
\hline & & & & & & & \\
\hline & 0 & 60 & 100 & 60 & 100 & & \\
\hline \multicolumn{8}{|c|}{21 dias de idade } \\
\hline TMP $(\mathrm{g})$ & 15,0 & 15,0 & 15,4 & 15,0 & 15,5 & 7,82 & ns \\
\hline$F P(g)$ & 3,84 & 4,02 & 4,03 & 3,80 & 4,09 & 11,5 & ns \\
\hline $\operatorname{TDP}(\mathrm{g})$ & 2,86 & 2,82 & 3,07 & 2,74 & 3,00 & 20,4 & ns \\
\hline TDC $(\mathrm{cm})$ & 6,54 & 6,51 & 6,68 & 6,54 & 6,59 & 3,90 & ns \\
\hline TDL $(\mathrm{cm})$ & 0,60 & 0,59 & 0,62 & 0,59 & 0,60 & 9,04 & ns \\
\hline TEP $(\mathrm{cm})$ & 2,89 & 2,79 & 3,02 & 2,87 & 3,15 & 16,2 & ns \\
\hline TEC $(\mathrm{cm})$ & 6,52 & 6,47 & 6,59 & 6,52 & 6,62 & 3,77 & ns \\
\hline TEL $(\mathrm{cm})$ & 0,62 & 0,63 & 0,65 & 0,61 & 0,63 & 10,7 & ns \\
\hline \multicolumn{8}{|c|}{42 dias de idade } \\
\hline TMP (g) & 38,2 & 39,4 & 39,1 & 40,3 & 41,03 & 8,57 & ns \\
\hline $\mathrm{FP}(\mathrm{g})$ & 13,4 & 12,3 & 13,8 & 13,1 & 12,2 & 16,7 & ns \\
\hline $\operatorname{TDP}(\mathrm{g})$ & 7,01 & 7,09 & 6,62 & 6,93 & 6,92 & 10,0 & ns \\
\hline $\operatorname{TDC}(\mathrm{cm})$ & 9,95 & 9,84 & 9,84 & 9,93 & 9,94 & 3,22 & ns \\
\hline TDL $(\mathrm{cm})$ & 0,93 & 0,94 & 0,95 & 0,99 & 0,94 & 8,02 & ns \\
\hline TEP $(\mathrm{cm})$ & 7,34 & 6,96 & 6,84 & 7,01 & 7,30 & 10,6 & ns \\
\hline TEC $(\mathrm{cm})$ & 9,98 & 9,89 & 9,89 & 9,94 & 9,94 & 3,03 & ns \\
\hline TEL $(\mathrm{cm})$ & 0,94 & 0,93 & 0,96 & 0,99 & 1,00 & 8,19 & ns \\
\hline
\end{tabular}

TMP $=$ Tarso-metatarso peso, FP $=$ Falanges peso, $T D P=$ Tíbia direita peso, TDC $=$ Tíbia direita comprimento, TDL $=$ Tíbia direita largura, TEP =Tíbia esquerda peso, TEC = Tíbia esquerda comprimento, TEL = Tíbia esquerda largura, $\mathrm{CV}(\%)=$ Coeficiente de variação, $\mathrm{P}=$ Probabilidade, $\mathrm{ns}=$ Efeito não significativo.

Tabela 8. Valores médios para as características ósseas de frangos de corte aos 21 e aos 42 dias de idade, conforme níveis de zinco orgânico na dieta (Experimento 1).

Table 8. Mean values for the bone characteristics of broilers at 21 and 42 days of age, according to levels of organic zinc in the diet (Experiment 1).

\begin{tabular}{|c|c|c|c|c|c|c|c|}
\hline \multirow[t]{2}{*}{ Variável } & \multicolumn{5}{|c|}{ Zinco orgânico (mg/kg) } & \multirow{2}{*}{$\begin{array}{l}\text { CV } \\
(\%)\end{array}$} & \multirow{2}{*}{$\begin{array}{r}\text { Valor } \\
\mathrm{P} \\
\end{array}$} \\
\hline & 20 & 40 & 60 & 80 & 100 & & \\
\hline \multicolumn{8}{|c|}{21 dias de idade } \\
\hline TMP $(g)$ & 14,2 & 15,2 & 15,0 & 15,5 & 15,5 & 7,82 & ns \\
\hline $\mathrm{FP}(\mathrm{g})$ & 3,81 & 3,90 & 3,80 & 4,13 & 4,09 & 11,5 & $\mathrm{~ns}$ \\
\hline $\operatorname{TDP}(\mathrm{g})$ & 2,57 & 2,69 & 2,74 & 3,06 & 3,00 & 20,4 & $\mathrm{~ns}$ \\
\hline $\operatorname{TDC}(\mathrm{cm})$ & 6,46 & 5,43 & 6,54 & 6,70 & 6,59 & 3,90 & $\mathrm{~ns}$ \\
\hline TDL (cm) & 0,59 & 0,61 & 0,59 & 0,61 & 0,60 & 9,04 & $\mathrm{~ns}$ \\
\hline TEP $(\mathrm{cm})$ & 2,73 & 2,92 & 2,87 & 3,01 & 3,15 & 16,2 & $\mathrm{~ns}$ \\
\hline TEC $(\mathrm{cm})$ & 6,43 & 6,48 & 6,52 & 6,74 & 6,62 & 3,77 & $\mathrm{~ns}$ \\
\hline TEL $(\mathrm{cm})$ & 0,65 & 0,63 & 0,61 & 0,66 & 0,63 & 10,7 & ns \\
\hline \multicolumn{8}{|c|}{42 dias de idade } \\
\hline TMP (g) & 39,5 & 41,5 & 40,3 & 40,0 & 41,0 & 8,6 & ns \\
\hline $\mathrm{FP}(\mathrm{g})$ & 11,0 & 12,5 & 13,1 & 12,3 & 12,2 & 16,7 & ns \\
\hline $\operatorname{TDP}(\mathrm{g})$ & 7,11 & 7,48 & 6,93 & 7,18 & 6,92 & 10,0 & ns \\
\hline TDC $(\mathrm{cm})$ & 9,99 & 10,3 & 9,93 & 10,1 & 9,94 & 3,22 & $\mathrm{~ns}$ \\
\hline TDL $(\mathrm{cm})$ & 0,96 & 0,99 & 0,99 & 0,96 & 0,94 & 8,02 & ns \\
\hline TEP $(\mathrm{cm})$ & 7,09 & 7,64 & 7,01 & 6,92 & 7,30 & 10,6 & ns \\
\hline TEC (cm) & 10,0 & 10,27 & 9,94 & 10,17 & 9,94 & 3,03 & ns \\
\hline TEL (cm) & 0,97 & 1,00 & 0,99 & 0,94 & 1,00 & 8,19 & $\mathrm{~ns}$ \\
\hline
\end{tabular}

$\overline{\mathrm{TMP}}=$ Tarso-metatarso peso, $\mathrm{FP}=$ Falanges peso, $\mathrm{TDP}=$ Tíbia direita peso, TDC $=$ Tíbia direita comprimento, $\mathrm{TDL}=$ Tíbia direita largura, TEP = Tíbia esquerda peso, TEC = Tíbia esquerda comprimento, TEL = Tíbia esquerda largura, $\mathrm{CV}(\%)=$ Coeficiente de variação, $\mathrm{P}=$ Probabilidade, $\mathrm{ns}=$ Efeito não significativo. 
Tabela 9. Valores médios para o teor de zinco na tíbia, no tarso-metatarso e nas falanges das aves aos 21 e 42 dias idade, conforme níveis de zinco na fonte orgânica e inorgânica na dieta (Experimento 1).

Table 9. Mean values for zinc content in the tibia, tarsal metatarsus, and phalanges of birds at 21 and 42 days old, according to zinc levels in organic and inorganic sources in the diet (Experiment 1).

\begin{tabular}{|c|c|c|c|c|c|c|c|}
\hline \multirow{3}{*}{ Variável } & \multicolumn{5}{|c|}{ Zinco $(\mathrm{mg} / \mathrm{kg})$} & \multirow{3}{*}{$\begin{array}{l}\text { CV } \\
\text { (\%) }\end{array}$} & \multirow{3}{*}{$\begin{array}{c}\text { Valor } \\
\text { P }\end{array}$} \\
\hline & \multicolumn{3}{|c|}{ Inorgânico } & \multicolumn{2}{|c|}{ Orgânico } & & \\
\hline & 0 & 60 & 100 & 60 & 100 & & \\
\hline \multicolumn{8}{|c|}{21 dias de idade } \\
\hline TD (mg/kg) & $150,2 b$ & $224,6 a$ & $219,7 a$ & $206,5 a$ & $233,4 a$ & 12,4 & 0,0004 \\
\hline TE $(\mathrm{mg} / \mathrm{kg})$ & $128,5 b$ & $201,1 a$ & $181,4 a b$ & $178,9 a b$ & $194,8 \mathrm{a}$ & 19,2 & 0,0239 \\
\hline TM (mg/kg) & 181,2 & 205,2 & 199,9 & 200,9 & 216,7 & 20,1 & ns \\
\hline $\mathrm{FA}(\mathrm{mg} / \mathrm{kg})$ & 197,3 & 206,0 & 234,7 & 215,1 & 216,7 & 14,2 & ns \\
\hline \multicolumn{8}{|c|}{42 dias de idade } \\
\hline TD (mg/kg) & 197,2 & 188,8 & 197,8 & 195,1 & 204,2 & 11,0 & ns \\
\hline TE (mg/kg) & 194,9 & 205,1 & 192,7 & 189,8 & 199,9 & 5,7 & ns \\
\hline TM (mg/kg) & 104,9 & 109,5 & 97,8 & 110,6 & 101,7 & 22,3 & ns \\
\hline $\mathrm{FA}(\mathrm{mg} / \mathrm{kg})$ & 86,2 & 88,1 & 86,8 & 92,0 & 98,6 & 9,10 & ns \\
\hline
\end{tabular}

$\mathrm{TD}=$ Tíbia direita (sem gordura), $\mathrm{TE}=$ Tíbia esquerda (com gordura), $\mathrm{TM}=$ Tarso-metatarso (sem gordura), FA = Falanges (sem gordura), $\mathrm{CV}(\%)=$ Coeficiente de variação, $\mathrm{P}=$ Probabilidade, ns = Efeito não significativo. Médias seguidas por letras não idênticas, na linha, diferem entre si ao nível de $5 \%$ de probabilidade pelo Teste de Tukey.

O maior teor de zinco foi encontrado na tíbia das aves que receberam a maior inclusão deste micromineral, pode-se observar efeito linear da concentração de zinco na tíbia esquerda. STAR et al. (2012) ao analisarem o teor de zinco na tíbia, observaram que o zinco orgânico foi caracterizado por uma maior biodisponibilidade (164\%) do que o zinco inorgânico (100\%). Já no estudo de LIU et al. (2013) foi de $116 \%$ em comparação com o sulfato de zinco (100\%). BROOKS et al. (2013) e SAHRAEl et al. (2013) também relataram a alta biodisponibilidade relativa de $\mathrm{Zn}$ fornecida na forma orgânica.

Ao se determinar a exigência de zinco na forma orgânica (Tabela 10), houve efeito quadrático $(p<0,03)$ na tíbia direita $(Y=0,0096 X 2-0,6532 X+202,83(T D Z n O))$.

Tabela 10. Valores médios para o teor de zinco na tíbia, no tarso-metatarso e nas falanges das aves aos 21 e 42 dias idade, conforme níveis de zinco orgânico na dieta.

Table 10. Mean values for zinc content in tibia, tarsal metatarsus, and phalanges of birds at 21 and 42 days old, according to levels of organic zinc in the diet.

\begin{tabular}{|c|c|c|c|c|c|c|c|}
\hline \multirow[t]{2}{*}{ Variável } & \multicolumn{5}{|c|}{ Zinco orgânico (mg/kg) } & \multirow{2}{*}{$\begin{array}{l}\text { CV } \\
(\%)\end{array}$} & \multirow{2}{*}{$\begin{array}{c}\text { Valor } \\
\text { P }\end{array}$} \\
\hline & 20 & 40 & 60 & 80 & 100 & & \\
\hline \multicolumn{8}{|c|}{21 dias de idade } \\
\hline TD (mg/kg) & $196,2 a b$ & $183,9 b$ & $206,5 a b$ & $208,8 a b$ & $233,4 a$ & 10,7 & 0,03 \\
\hline TE (mg/kg) & 178,5 & 147,2 & 178,9 & 173,9 & 194,8 & 17,5 & ns \\
\hline TM(mg/kg) & 188,6 & 202,2 & 200,9 & 176,2 & 216,7 & 19,0 & ns \\
\hline $\mathrm{FA}(\mathrm{mg} / \mathrm{kg})$ & 231,3 & 222,4 & 215,1 & 208,0 & 216,7 & 11,0 & ns \\
\hline \multicolumn{8}{|c|}{42 dias de idade } \\
\hline TD (mg/kg) & 184,9 & 183,1 & 195,1 & 192,4 & 204,2 & 10,8 & ns \\
\hline TE (mg/kg) & 188,0 & 190,9 & 189,8 & 208,9 & 199,9 & 8,7 & ns \\
\hline TM (mg/kg) & 106,5 & 98,9 & 110,6 & 131,2 & 101,7 & 21,2 & ns \\
\hline $\mathrm{FA}(\mathrm{mg} / \mathrm{kg})$ & 92,5 & 94,8 & 92,0 & 88,6 & 98,6 & 8,02 & ns \\
\hline
\end{tabular}

$\mathrm{TD}=$ Tíbia direita (sem gordura), TE = Tíbia esquerda (com gordura), $\mathrm{TM}=$ Tarso-metatarso (sem gordura), FA = Falanges (sem gordura), $\mathrm{CV}(\%)=$ Coeficiente de variação, $\mathrm{P}=$ Probabilidade, $\mathrm{ns}=$ Efeito não significativo. Médias seguidas por letras não idênticas, na linha, diferem entre si ao nível de $5 \%$ de probabilidade pelo Teste de Tukey.

De acordo com HUANG et al. (2007), HUANG et al. (2009) e AO et al. (2009) a suplementação de zinco na dieta resultou em aumento da concentração de zinco na tíbia, assemelhando-se aos resultados encontrados no presente trabalho em que houve um aumento de zinco no osso conforme elevou-se a concentração de zinco na dieta.

Discordando de GOMES et al. (2008) que observaram efeito quadrático dos níveis de zinco na tíbia, estimando como exigência $44,00 \mathrm{mg} / \mathrm{kg}$ e $86,12 \mathrm{mg} / \mathrm{kg}$, respectivamente. GOMES et al. (2009) relataram que devido a carência de estudos sobre níveis de zinco para frangos de corte das linhagens atuais associando-os a formação óssea, não permite maiores comparações e denota a necessidade de mais 
pesquisas nessa área. De acordo com SUTTLE (2010) as revisões anteriores não forneceram provas para um benefício consistente de fornecer o zinco como complexos orgânicos em vez de sais inorgânicos simples.

No experimento 2, testando o micromineral manganês, não houve efeito $(p>0,05)$ para a tíbia direita e esquerda (peso, comprimento e altura) e no peso do tarso-metatarso e das falanges (Tabelas 11 e 12). Concordando com SUNDER et al. (2013) os quais não encontraram diferenças no peso e comprimento das tíbias, indicando a não influência do mineral orgânico e reafirmando que a suplementação mínima de manganês foi suficiente para manter uma boa estrutura óssea (SUNDER et al. 2011).

Tabela 11. Valores médios para as características ósseas de frangos de corte aos 21 e aos 42 dias de idade, conforme níveis de manganês na fonte orgânica e inorgânica na dieta (Experimento 2).

Table 11. Mean values for the bone characteristics of broiler chickens at 21 and 42 days of age, according to manganese levels in organic and inorganic sources in the diet (Experiment 2).

\begin{tabular}{|c|c|c|c|c|c|c|c|}
\hline \multirow{3}{*}{ Variável } & \multicolumn{5}{|c|}{ Manganês (mg/kg) } & \multirow{3}{*}{$\mathrm{CV}(\%)$} & \multirow{3}{*}{ Valor $\mathrm{P}$} \\
\hline & \multicolumn{3}{|c|}{\begin{tabular}{l}
\multicolumn{2}{l}{ Inorgânico } \\
65
\end{tabular}} & \multicolumn{2}{|c|}{ Orgânico } & & \\
\hline & 0 & 65 & 105 & 65 & 105 & & \\
\hline \multicolumn{8}{|c|}{21 dias de idade } \\
\hline$\overline{\mathrm{TMP}}(\mathrm{g})$ & 145,0 & 15,3 & 14,9 & 14,7 & 15,5 & 8,35 & ns \\
\hline$F P(g)$ & 5,30 & 5,54 & 5,30 & 5,61 & 5,73 & 11,4 & ns \\
\hline $\operatorname{TDP}(\mathrm{g})$ & 2,22 & 2,25 & 2,22 & 2,32 & 2,27 & 8,75 & ns \\
\hline $\operatorname{TDC}(\mathrm{cm})$ & 6,58 & 6,60 & 6,65 & 6,69 & 6,69 & 3,34 & ns \\
\hline TDL $(\mathrm{cm})$ & 0,67 & 0,62 & 0,62 & 0,65 & 0,64 & 6,42 & ns \\
\hline TEP $(\mathrm{cm})$ & 2,26 & 0,27 & 2,25 & 2,25 & 2,25 & 8,96 & ns \\
\hline TEC $(\mathrm{cm})$ & 6,50 & 6,62 & 6,67 & 6,64 & 6,51 & 3,43 & ns \\
\hline TEL $(\mathrm{cm})$ & 0,63 & 0,61 & 0,61 & 0,62 & 0,64 & 6,91 & ns \\
\hline \multicolumn{8}{|c|}{42 dias de idade } \\
\hline TMP $(g)$ & 41,5 & 41,5 & 41,4 & 39,7 & 40,9 & 9,35 & ns \\
\hline$F P(g)$ & 14,9 & 15,2 & 15,2 & 15,3 & 15,3 & 10,1 & ns \\
\hline $\operatorname{TDP}(\mathrm{g})$ & 6,79 & 7,11 & 7,12 & 6,74 & 6,93 & 11,0 & ns \\
\hline $\operatorname{TDC}(\mathrm{cm})$ & 9,87 & 10,0 & 10,1 & 9,97 & 10,2 & 4,04 & ns \\
\hline TDL $(\mathrm{cm})$ & 0,93 & 1,01 & 0,97 & 0,93 & 0,95 & 8,55 & ns \\
\hline TEP $(\mathrm{cm})$ & 6,81 & 7,20 & 6,97 & 7,02 & 7,17 & 10,9 & ns \\
\hline TEC $(\mathrm{cm})$ & 9,86 & 10,1 & 10,1 & 9,98 & 10,0 & 3,95 & ns \\
\hline TEL $(\mathrm{cm})$ & 0,95 & 1,00 & 0,98 & 0,99 & 0,97 & 9,22 & ns \\
\hline
\end{tabular}

$\overline{\mathrm{TMP}}=$ Tarso-metatarsopeso, FP $=$ Falanges peso, TDP $=$ Tíbia direita peso, TDC $=$ Tíbia direita comprimento, TDL $=$ Tíbia direita largura, TEP = Tíbia esquerda peso, TEC = Tíbia esquerda comprimento, TEL = Tíbia esquerda largura, $\mathrm{CV}(\%)=$ Coeficiente de variação, $\mathrm{P}=$ Probabilidade, $\mathrm{ns}=$ Efeito não significativo.

Avaliando-se a disponibilidade de manganês para frangos de corte aos 21 dias de idade, houve efeito do teor de manganês $(p<0,03)$ para tíbia direita $(Y=0,0179 X+5,4246$ (TDMn I - Tíbia direita manganês inorgânico) e $Y=0,0139 X+5,3461))$ e $(p<0,01)$ para a tíbia esquerda $(Y=0,0138 X+4,3456$ (TEMn I Tíbia esquerda manganês inorgânico) e $Y=0,0104 X+4,3893$ (TEMnO - Tíbia esquerda manganês orgânico) (Tabela 13). Não houve resposta $(p>0,05)$ do teor de manganês contido no tarso-metatarso e nas falanges das aves aos 21 dias de idade (Tabela 13).

Para as aves aos 42 dias de idade, houve efeito para a tíbia direita $(p<0,01)(Y=0,0062 X+3,4249$ (TDMnl) e $Y=0,0121 X+3,4215$ (TDMnO)) e para as falanges $(p<0,0006)$ em relação ao teor de manganês $(Y=0,037 X+1,0842(F M n l)$ e $Y=0,076 X+1,0287(F M n O))($ Tabela 13). Não houve resposta $(p>0,05)$ para a tíbia esquerda e para o tarso-metatarso (Tabela 13). A biodisponibilidade do manganês encontrada foi de $195 \%$ para tíbia direita e de $205 \%$ nas falanges.

Não houve efeito $(p>0,05)$ para o teor de manganês aos 21 e aos 42 dias de idade das aves para as variáveis: tíbia direita, tíbia esquerda, tarso-metatarso e falanges (Tabela 14).

De acordo com SUTTLE (2010) em um período de 10 anos (de 2000 a 2010) enorme quantidade de publicações sobre os méritos das fontes orgânicas de manganês foram vistas. No entanto, os resultados são difíceis de interpretar devido à grande variedade de complexos testados, as circunstâncias incomuns de alguns testes e a variedade de respostas utilizadas nos testes. É improvável que a adição de fontes orgânicas de manganês à dieta de aves melhore a saúde ou a produção quando comparada com um sal ou óxido inorgânico. Os recursos anteriores de pesquisa e desenvolvimento não devem mais ser desperdiçados na perseguição de vantagens triviais para os quelatos de manganês. 
Tabela 12. Valores médios para as características ósseas de frangos de corte aos 21 e aos 42 dias de idade, conforme níveis de manganês orgânico na dieta (Experimento 2).

Table 12. Mean values for the bone characteristics of broilers at 21 and 42 days of age, according to levels of organic manganese in the diet (Experiment 2).

\begin{tabular}{|c|c|c|c|c|c|c|c|}
\hline \multirow[t]{2}{*}{ Variável } & \multicolumn{5}{|c|}{ Manganês orgânico (mg/kg) } & \multirow{2}{*}{$\begin{array}{l}\text { CV } \\
(\%)\end{array}$} & \multirow{2}{*}{$\begin{array}{c}\text { Valor } \\
\text { P }\end{array}$} \\
\hline & 25 & 45 & 65 & 85 & 105 & & \\
\hline \multicolumn{8}{|c|}{21 dias de idade } \\
\hline TMP $(\mathrm{g})$ & 14,4 & 15,4 & 14,7 & 15,3 & 15,5 & 8,35 & ns \\
\hline $\mathrm{FP}(\mathrm{g})$ & 5,04 & 5,16 & 5,61 & 5,73 & 5,73 & 11,4 & ns \\
\hline $\operatorname{TDP}(\mathrm{g})$ & 2,15 & 2,22 & 2,32 & 2,25 & 2,27 & 8,75 & ns \\
\hline TDC (cm) & 6,54 & 6,61 & 6,69 & 6,68 & 6,69 & 3,34 & ns \\
\hline TDL (cm) & 0,63 & 0,64 & 0,65 & 0,65 & 0,64 & 6,42 & ns \\
\hline $\operatorname{TEP}(\mathrm{cm})$ & 2,17 & 2,23 & 2,25 & 2,31 & 2,25 & 8,96 & ns \\
\hline TEC $(\mathrm{cm})$ & 6,51 & 6,55 & 6,64 & 6,71 & 6,51 & 3,43 & ns \\
\hline TEL (cm) & 0,62 & 0,63 & 0,62 & 0,63 & 0,64 & 6,91 & ns \\
\hline \multicolumn{8}{|c|}{42 dias de idade } \\
\hline TMP $(g)$ & 41,2 & 40,6 & 39,7 & 38,5 & 41,0 & 9,35 & ns \\
\hline $\mathrm{FP}(\mathrm{g})$ & 15,2 & 15,7 & 15,3 & 15,4 & 15,3 & 10,1 & ns \\
\hline $\operatorname{TDP}(\mathrm{g})$ & 6,45 & 7,04 & 6,74 & 6,63 & 6,93 & 11,0 & $\mathrm{~ns}$ \\
\hline $\operatorname{TDC}(\mathrm{cm})$ & 9,88 & 10,0 & 9,97 & 10,0 & 10,2 & 4,04 & ns \\
\hline TDL (cm) & 0,93 & 0,96 & 0,93 & 0,88 & 0,95 & 8,55 & ns \\
\hline TEP (cm) & 6,48 & 7,04 & 7,02 & 6,78 & 7,17 & 10,9 & ns \\
\hline TEC (cm) & 9,89 & 9,93 & 9,98 & 9,97 & 10,0 & 3,95 & ns \\
\hline TEL (cm) & 0,92 & 0,99 & 0,99 & 0,94 & 0,97 & 9,22 & ns \\
\hline
\end{tabular}

TMP $=$ Tarso-metatarso peso, $\mathrm{FP}=$ Falanges peso, $\mathrm{TDP}=$ Tíbia direita peso, TDC $=$ Tíbia direita comprimento, $\mathrm{TDL}=$ Tíbia direita largura, TEP = Tíbia esquerda peso, TEC = Tíbia esquerda comprimento, TEL = Tíbia esquerda largura, $\mathrm{CV}(\%)=$ Coeficiente de variação, $\mathrm{P}=$ Probabilidade, $\mathrm{ns}=$ Efeito não significativo.

Tabela 13. Valores médios para o teor de manganês na tíbia, no tarso-metatarso e nas falanges das aves aos 21 e 42 dias idade, conforme níveis de manganês orgânico e inorgânico na dieta (Experimento 2).

Table 13. Mean values for manganese content in the tibia, tarsal metatarsus, and phalanges of birds at 21 and 42 days old, according to levels of organic and inorganic manganese in the diet (Experiment 2).

\begin{tabular}{|c|c|c|c|c|c|c|c|}
\hline \multirow{3}{*}{ Variável } & \multicolumn{5}{|c|}{ Manganês (mg/kg) } & \multirow{3}{*}{$\begin{array}{l}\text { CV } \\
(\%)\end{array}$} & \multirow{3}{*}{$\begin{array}{c}\text { Valor } \\
\text { P }\end{array}$} \\
\hline & \multicolumn{3}{|c|}{ Inorgânico } & \multicolumn{2}{|c|}{ Orgânico } & & \\
\hline & 0 & 65 & 105 & 65 & 105 & & \\
\hline \multicolumn{8}{|c|}{21 dias de idade } \\
\hline TD (mg/kg) & $5,30 b$ & $6,26 a b$ & $7,21 a$ & $6,37 a b$ & 6,73ab & 13,5 & 0,03 \\
\hline TE (mg/kg) & $4,35 b$ & $5,23 a b$ & $5,80 a$ & $5,17 a b$ & $5,42 a b$ & 11,3 & 0,01 \\
\hline TM (mg/kg) & 2,30 & 2,61 & 3,07 & 2,74 & 2,81 & 26,3 & ns \\
\hline $\mathrm{FA}(\mathrm{mg} / \mathrm{kg})$ & 1,87 & 3,07 & 2,62 & 2,61 & 2,93 & 29,5 & ns \\
\hline \multicolumn{8}{|c|}{42 dias de idade } \\
\hline TD (mg/kg) & $3,39 b$ & 3,92ab & 4,02ab & $4,29 a b$ & $4,64 a$ & 12,7 & 0,01 \\
\hline TE (mg/kg) & 3,17 & 4,41 & 3,88 & 3,90 & 4,22 & 20,2 & ns \\
\hline TM (mg/kg) & 1,85 & 1,89 & 1,83 & 1,92 & 1,92 & 28,6 & ns \\
\hline $\mathrm{FA}(\mathrm{mg} / \mathrm{kg})$ & $1,04 \mathrm{c}$ & $1,44 a b c$ & $1,40 \mathrm{bc}$ & $1,49 a b$ & $1,84 a$ & 15,7 & 0,0006 \\
\hline \multicolumn{8}{|c|}{$\begin{array}{l}\mathrm{TD}=\text { Tíbia direita }(\text { sem gordura), } \mathrm{TE}=\text { Tíbia esquerda }(\mathrm{com} \text { gordura), TM = Tarso-metatarso (sem gordura), FA = } \\
\text { Falanges (sem gordura), } \mathrm{CV}(\%)=\text { Coeficiente de variação, } \mathrm{P}=\text { Probabilidade, ns = Efeito não significativo. Médias } \\
\text { seguidas por letras não idênticas diferem, na linha, entre si ao nível de } 5 \% \text { de probabilidade pelo Teste de Tukey. }\end{array}$} \\
\hline \multicolumn{8}{|c|}{$\begin{array}{l}\text { Nas condições experimentais do estudo de PACHECO et al. (2017) os requisitos de zinco e } \\
\text { manganês para o desempenho de frangos de corte no período de } 1 \text { a } 42 \text { dias de idade foram supridos sem } \\
\text { adição de zinco ou manganês (independente da forma: orgânica ou inorgânica). Contudo, sob condições } \\
\text { comerciais de criação, que são mais desafiadoras, o uso de níveis superiores a } 33,00 \mathrm{mg} / \mathrm{kg} \mathrm{e} 37,80 \mathrm{mg} / \mathrm{kg} \\
\text { de zinco e manganês, respectivamente pode ser justificada. }\end{array}$} \\
\hline
\end{tabular}


Tabela 14. Valores médios para o teor de manganês na tíbia, no tarso-metatarso e nas falanges das aves aos 21 e 42 dias idade, conforme níveis de manganês na fonte orgânica na dieta.

Table 14. Mean values for manganese content in the tibia, tarsal metatarsal, and phalanges of birds at 21 and 42 days old, according to levels of manganese in the organic source in the diet.

\begin{tabular}{|c|c|c|c|c|c|c|c|}
\hline \multirow[t]{2}{*}{ Variável } & \multicolumn{5}{|c|}{ Manganês orgânico (mg/kg) } & \multirow{2}{*}{$\begin{array}{l}\text { CV } \\
\text { (\%) }\end{array}$} & \multirow{2}{*}{$\begin{array}{c}\text { Valor } \\
\text { P }\end{array}$} \\
\hline & 25 & 45 & 65 & 85 & 105 & & \\
\hline \multicolumn{8}{|c|}{21 dias de idade } \\
\hline $\mathrm{TD}(\mathrm{mg} / \mathrm{kg})$ & 5,79 & 6,13 & 6,37 & 7,08 & 6,73 & 11,3 & ns \\
\hline TE $(\mathrm{mg} / \mathrm{kg})$ & 4,90 & 5,14 & 5,17 & 5,77 & 5,42 & 12,2 & ns \\
\hline $\mathrm{TM}(\mathrm{mg} / \mathrm{kg})$ & 2,53 & 2,47 & 2,74 & 2,94 & 2,81 & 28,2 & ns \\
\hline $\mathrm{FA}(\mathrm{mg} / \mathrm{kg})$ & 2,25 & 2,23 & 2,61 & 2,90 & 2,93 & 27,1 & ns \\
\hline \multicolumn{8}{|c|}{42 dias de idade } \\
\hline TD $(\mathrm{mg} / \mathrm{kg})$ & 4,76 & 4,22 & 4,29 & 4,67 & 4,64 & 11,9 & ns \\
\hline TE (mg/kg) & 4,21 & 3,77 & 3,90 & 4,46 & 4,22 & 9,70 & ns \\
\hline TM (mg/kg) & 1,92 & 1,84 & 1,92 & 2,10 & 1,92 & 15,2 & ns \\
\hline $\mathrm{FA}(\mathrm{mg} / \mathrm{kg})$ & 1,60 & 1,51 & 1,49 & 1,78 & 1,84 & 11,7 & $\mathrm{~ns}$ \\
\hline
\end{tabular}

$\mathrm{TD}=$ Tíbia direita (sem gordura), $\mathrm{TE}=$ Tíbia esquerda (com gordura), $\mathrm{TM}=$ Tarso-metatarso (sem gordura), $\mathrm{FA}=$ Falanges (sem gordura), $\mathrm{CV}(\%)=$ Coeficiente de variação, $\mathrm{P}=$ Probabilidade, $\mathrm{ns}=$ Efeito não significativo.

\section{Comparação dos métodos para avaliar mineralização óssea.}

No experimento 1, comparando-se as diferentes metodologias estudadas houve efeito $(p<0,0001)$ do zinco orgânico e inorgânico para as aves aos 42 dias de idade, onde o grau de mineralização encontrado nas tíbias (com e sem extração de gordura) diferiram do tarso-metatarso e das falanges (com extração de gordura) (Tabela 15).

Tabela 15. Comparação das diferentes metodologias avaliadas, conforme o nível de zinco orgânico e inorgânico recomendado nas dietas de frango de corte (Experimento 2).

Table 15. Comparison of the different methodologies evaluated, according to the level of organic and inorganic zinc recommended in broiler diets (Experiment 2).

\begin{tabular}{|c|c|c|c|c|}
\hline \multirow{3}{*}{ Variável } & \multicolumn{4}{|c|}{$60 \mathrm{mg} / \mathrm{kg}$ de Zinco } \\
\hline & \multicolumn{2}{|c|}{ Orgânico } & \multicolumn{2}{|c|}{ Inorgânico } \\
\hline & 21 dias & 42 dias & 21 dias & 42 dias \\
\hline TSG (mg) & 206,5 & $195,1 \mathrm{a}$ & 224,6 & $188,8 \mathrm{a}$ \\
\hline TCG (mg) & 178,9 & $189,8 \mathrm{a}$ & 201,1 & 205,1 a \\
\hline $\mathrm{TM}(\mathrm{mg})$ & 200,9 & $110,6 \mathrm{~b}$ & 205,2 & $109,5 b$ \\
\hline$F(\mathrm{mg})$ & 215,1 & $92,0 \mathrm{~b}$ & 206,0 & $88,1 \mathrm{~b}$ \\
\hline CV (\%) & 17,5 & 10,6 & 14,6 & 12,4 \\
\hline Valor de $\mathrm{P}$ & ns & $<0,0001$ & ns & $<0,0001$ \\
\hline
\end{tabular}

TSG = Tíbia sem gordura, TCG = Tíbia com gordura, TM = Tarso-metatarso, F = Falanges, CV $(\%)=$ Coeficiente de variação, $\mathrm{P}=$ Probabilidade, $\mathrm{ns}=$ Efeito não significativo. Médias seguidas por letras não idênticas, na coluna, diferem entre si ao nível de $5 \%$ de probabilidade pelo Teste de Tukey.

No experimento 2, comparando-se as diferentes metodologias estudadas, pode-se observar efeito estatístico $(p<0,0001)$ em relação ao grau de mineralização óssea para todas as variáveis avaliadas.

Para o manganês orgânico aos 21 dias de idade, houve diferença entre a as tíbias, as quais também diferiram no grau de mineralização do tarso-metatarso e das falanges. Não houve diferença estatística entre a mineralização do tarso-metatarso e das falanges.

Para o manganês orgânico aos 42 dias e para o inorgânico aos 21 e 42 dias, o grau de mineralização encontrado nas tíbias (com e sem extração de gordura) diferiram do tarso-metatarso e das falanges (com extração de gordura) (Tabela 16).

Nos dois experimentos, em relação ao tempo de execução das diferentes metodologias, gastou-se maior tempo para retirada da tíbia do que para retirada do tarso-metatarso e das falanges pelo fato de ter que descarnar a tíbia. O tempo gasto para secagem das amostras foi de 72 horas para as diferentes variáveis estudadas.

Para as variáveis: tíbia direita, tarso-metatarso e falanges, as quais foram realizadas a extração lipídica, gastou-se oito horas a mais quando comparada a tíbia esquerda, a qual não foi realizada a extração lipídica.

Em relação à queima das amostras, o tempo total gasto foi de sete horas para todas as variáveis. 
Sendo assim, pode-se dizer que o menor tempo de execução entre as diferentes metodologias estudadas foi para o método que não foi efetuada a extração lipídica da amostra.

Tabela 16. Comparação das diferentes metodologias avaliadas, conforme o nível de manganês orgânico e inorgânico recomendado nas dietas de frango de corte (Experimento 2).

Table 16. Comparison of the different methodologies evaluated, according to the level of organic and inorganic manganese recommended in broiler diets (Experiment 2).

\begin{tabular}{|c|c|c|c|c|}
\hline \multirow{3}{*}{ Variável } & \multicolumn{4}{|c|}{$65 \mathrm{mg} / \mathrm{kg}$ de Manganês } \\
\hline & \multicolumn{2}{|c|}{ Orgânico } & \multicolumn{2}{|c|}{ Inorgânico } \\
\hline & 21 dias & 42 dias & 21 dias & 42 dias \\
\hline TSG (mg) & $6,37 \mathrm{a}$ & $4,29 a$ & $6,26 \mathrm{a}$ & $3,92 \mathrm{a}$ \\
\hline TCG (mg) & $5,17 \mathrm{~b}$ & $3,90 a$ & $5,23 a$ & $3,71 \mathrm{a}$ \\
\hline $\mathrm{TM}(\mathrm{mg})$ & $2,74 \mathrm{c}$ & $1,92 \mathrm{~b}$ & $2,61 \mathrm{~b}$ & $1,89 \mathrm{~b}$ \\
\hline$F(\mathrm{mg})$ & $2,61 \mathrm{c}$ & $1,49 b$ & $3,07 \mathrm{~b}$ & $1,44 \mathrm{~b}$ \\
\hline CV (\%) & 12,5 & 15,3 & 17,5 & 11,6 \\
\hline Valor de $\mathrm{P}$ & $<0,0001$ & $<0,0001$ & $<0,0001$ & $<0,0001$ \\
\hline
\end{tabular}

$\overline{T S G}=$ Tíbia sem gordura, $T C G=$ Tíbia com gordura. $T M=$ Tarso-metatarso, $F=$ Falanges, CV $(\%)=$ Coeficiente de variação, $P=$ Probabilidade, ns = Efeito não significativo. Médias seguidas por letras não idênticas, na coluna, diferem entre si ao nível de $5 \%$ de probabilidade pelo Teste de Tukey.

A técnica mais utilizada é com a tíbia desengordurada, entretanto pelos resultados pode-se determinar zinco e manganês na tíbia sem a extração de gordura uma vez que não houve diferença estatística para a tíbia sem gordura.

\section{CONCLUSÃO}

Independente da fonte e nível utilizado, os microminerais estudados (zinco e manganês) não interferiram nas características ósseas avaliadas (peso, comprimento e largura da tíbia, peso do tarsometatarso e peso das falanges).

Em ambos os estudos, o grau de mineralização óssea aumentou conforme elevou-se a concentração de zinco ou de manganês na dieta, independente da fonte em que estes microminerais foram estudados (orgânica ou inorgânica). de tíbias.

O método mais adequado para determinação do teor de zinco e de manganês é através da utilização

Não há necessidade de extração de gordura da tíbia para determinação do teor de zinco ou de manganês e a análise pode ser realizada com menor tempo de execução sem detrimento dos resultados.

\section{REFERÊNCIAS}

AO T et al. 2009. Effects of feeding different forms of zinc and copper on the performance and tissue mineral content of chicks. Poultry Science 88: 2171-2175.

AOAC. 1995. Association of Official Analytical Chemists. Official Methods of Analysis. 16.ed. v.2. Arlington: AOAC. 474p. AOAC. 2000. Association of Official Analytical Chemists. Official Methods of Analysis. 17.ed. Washington: AOAC. p.6162.

BAO YM \& CHOCT M. 2009. Trace mineral nutrition for broiler chickens and prospects of application of organically complexed trace mineral: a review. Animal Production Science 49: 269-282.

BROOKS MA et al. 2013. Bioavailability in chicks of zinc from zinc propionate. The Journal of Applied Poultry Research 22: 153-159.

GARCIA AR \& DALE N. 2004. Foot ash as na effective diagnostic tool to evaluate boné mineralization problems in broiler chickens. In: International Poultry Scientific Forum. Abstracts.... Georgia: University of Georgia. p.1782.

GARCIA AR \& DALE NM. 2006. Foot ash as a means of quantifying bone mineralization in chicks. The Journal of Applied Poultry Research 15: 103-109.

GOMES PC et al. 2008. Exigências nutricionais de zinco para frangos de corte machos e fêmeas na fase inicial. Revista Brasileira de Zootecnia 37: 79-83.

GOMES PC et al. 2009. Níveis nutricionais de zinco para frangos de corte machos e fêmeas nas fases de crescimento e terminação. Revista Brasileira de Zootecnia 38: 1719-1725.

HUANG YL et al. 2007. Na optimal dietary zinc level of broiler chicks fed a corn-soybean meal diet. Poultry Science 86: 2582-2589.

HUANG YL et al. 2009. Relative bioavailabilities of organic zinc sources with different chelation strengths for broilers fed a conventional corn-soybean meal diet. Journal of Animal Science 87: 2038-2046.

LIU SB et al. 2013. The effectiveness of zinc proteinate for chicks fed a conventional corn-soybean meal diet. The 
Journal of Applied Poultry Research 22: 396-403.

PACHECO et al. 2017. Dietary levels of zinc and manganese on the performance of broilers between 1 to 42 days of age. Revista Brasileira de Ciência Avícola 19: 171-178.

ROSTAGNO HS et al. 2005. Tabelas brasileiras para aves e suínos: composição de alimentos e exigências nutricionais. 2.ed. Viçosa: UFV. 186p.

SAKOMURA NK \& ROSTAGNO HS. 2007. Métodos de pesquisa em nutrição de monogástricos. Jaboticabal: FUNEP. 283p.

SAHRAEI M et al. 2013. Estimation of the relative bioavailability of several zinc sources for broilers fed a conventional corn-soybean meal diet. The Journal of Poultry Science 50: 53-59.

SAS. 2004. Statistical Analyses System. User's guide: statistic. 12.ed. New York: SCOTT ML \& Associates. 1686p.

STAR L et al. 2012. Bioavailability of organic and inorganic zinc sources in male broilers. Poultry Science 91: 3115-3120.

SUNDER GS et al. 2011. Effect of supplemental inorganic $\mathrm{Zn}$ and $\mathrm{Mn}$ and their interactions on the performance of broiler chicken, mineral bioavailability and imumune response. Biological Trace Element Research 139: 177-187.

SUNDER GS et al. 2013. Effect of supplemental organic Zn and Mn on broiler performance, bone measures, tissue mineral uptake and immune response at 35 days of age. Poultry Science 3: 1-11.

SUTTLE NF. 2010. Mineral nutrition of livestock. 4.ed. Oxfordshire: CABI. 587p.

SWIACTKIEWICZ S et al. 2014. The efficacy of organic minerals in poultry nutrition: review and implications of recent studies. World's Poultry Science Journal 70: 475-486.

YAN F et al. 2005. Comparison of methods to evaluate bone mineralization. The Journal of Applied Poultry Research 14: 492-498.

YAN F \& WALDROUP PW. 2006. Evaluation of Mintrex® manganese as a source of manganese for young broilers. International Journal of Poultry Science 5: 708-703. 